\title{
Writing Scientific Project Proposals in Ethnobotany: Tips and tricks
}

\author{
Valentina Savo, David Reedy \& Giancarlo Dente
}

\section{Editorial}

In addition to writing a good scientific paper, another skill that is very important for an ethnobotanist is the ability to write a good research project proposal. The variety and diversity of grant forms, requirements and guidelines makes it impossible to define a unique and universal set of guidelines for grant writing, but most of them require the same general information. Writing a grant proposal is a time consuming process which does not always result in funded projects. In this editorial, the authors will try to provide useful information specifically addressing one of the major challenges for beginning researchers in the field of ethnobotany: writing a good research project proposal. Informal interviews with experienced grant writers were carried out during three ethnobiology meetings in 2011, in order to collect "tips and tricks" that could be inspiring for other grant seekers. Obviously, this cannot be an exhaustive foray into the field of grant-writing. However, we hope this paper will help make grant writing easier by reducing time and result in a higher percentage of successful proposals.

While there are many books on the subject of grant writing (e.g., Browning 2008, Carlson \& O'Neal-McElrath 2008, Karsh \& Fox 2009, Nebiu 2002), ethnobotanical information is usually obtained from experienced people (or informants). In this paper, the authors, being ethnobotanists and grant writers, thought it might be useful to find information on grant writing from bibliographic sources, as well as from informants (other ethnobotanists). Finally, the authors hope to provide some help to people who have problems in finding grant writing manuals but have access to the Internet.

This paper is divided into two parts. The writing of a research proposal has a precise timetable and is usually composed of specific sections. These sections will be dis- cussed in the first part of the paper. The structure and content of this part reflects the general organization of bibliographic sources on the subject and the personal experiences of the authors. The second part discusses the comments ("tips and tricks") of ethnobotanists who have, to different extents, experience in grant writing. This information is summarized in a table of main concepts.

\section{Part 1}

The logical framework of a research project proposal should generally have the following structure: 1) aim; 2) objectives; 3) methodology; 4) expected results; 5) work packages; 6) work plan. This general framework contains the main points of the majority of grant proposals and follows, pro parte, the general design of scientific writing.

The timetable of a project proposal should be organized in relation to grant deadlines. A good strategy would be to have a database of potential funders and create a calendar of their deadlines. In this case, the planning of the

\section{Correspondence}

Valentina Savo, Department of Environmental Biology, University Roma Tre, Viale Marconi 446, I-00146, Rome, ITALY. vsavo@uniroma3.it

David Reedy, Botanical Research Institute of Texas, $1700 \mathrm{~N}$. University Drive, Fort Worth, Texas, 76107-3400, U.S.A., Department of Botany, University of Hawai'i at Mānoa, Honolulu, Hawai i 96822, U.S.A.

Giancarlo Dente, Giacomo Brodolini Foundation, Via Barberini 50, I-00187, Rome, ITALY.

Ethnobotany Research \& Applications 9:325-334 (2011)

Published: November 11, 2011 
writing of the project would be more organized. Moreover, it would increase the chances of submitting the proposal before the deadline, with the great advantage of having enough time to read and re-read the proposal, checking for inconsistencies, errors, and to find possible ways to make improvements. Also, it could be possible to have time to ask colleagues to read the proposal over: when writing a document for a continued period of time, it is natural to become too close to it. Moreover, external comments may help the grant writer to check if the project is clear and comprehendible to people who are not part of the same research group.

The timetable (preliminary and following actions) and section framework of a hypothetical project are outlined below.

\section{Preliminary actions}

Search for granting agencies. The first problem to face in writing a grant is to find the right foundation or granting agency. This may not constitute a great problem to researchers with a long and successful background of funded projects; however, this could represent a huge obstacle for less experienced ethnobiologists.

As a researcher in need of research funds it is easy to locate possible grants. However, it is important not to seek funding from foundations with a mission that does not match your intended research. It is better to find funding that fits the proposed project rather than altering the project to fit the foundation's mission. Checking into all possible funding sources, searching the Web for funding information, and writing good proposals, are key issues to obtain a successful grant (Browning 2008). This strategy is basically aimed at the preparation of "the right" proposal. Another solution would be to write many grant proposals in order to enhance the chance of raising funds.

Ethnobotany is considered a transversal discipline and ethnobotanical studies may have different aims and applications that span from medical to ethnographic research. This factor allows for certain flexibility in searching for granting agencies. However, an ethnobotanical grant proposal has to be specifically addressed: the project has to match with the specific aims, focus and requirements of each granting agency. So, it is generally not possible to submit the same grant application to different potential funders without making changes.

There are many granting agencies around the world that fund or promote ethnobotanical projects:

- National agencies (e.g., National Science Foundation-NSF)

- International agencies (e.g., European Union Commission)

- Scientific Societies (e.g., International Society for Ethnobiology)
- Non-Government Organizations and foundations (e.g., World Wildlife Fund) (searching the web using as keywords "ethnobotany", or related words, and "grants" could help you in finding other sources).

Guidelines. Understand their idea. The second step after finding the right grant is to read the grant application carefully. Sometimes, guidelines may be unclear: in this case, an easy and useful solution might be to write to the grant contact person and ask for clarification. Guidelines are a key issue. The grant writer has to follow them very carefully (it is especially important that the project will match the mission of the agency) and it could be useful to underline the points that seem to be important for the granting agency. Not many agencies have a specifically ethnobotanical focus, thus it is important to understand how your research may fit within their mission. For example, many agencies have a focus on preservation/conservation (of nature, environment, biodiversity, culture, etc.) and many ethnobotanical projects imply these concepts.

After this first step, grant seekers should start to collect the required materials (financial and administrative documents, permits and permissions, etc.).

Writing style. Make your idea understandable. The use of a pertinent language might be a key point, but sometimes it might be better to avoid the use of fancy words, complicated sentences or too technical terms, especially if the grant includes parts that are not closely related to the scientific background of the grant writer. It would be better to write in a simple but clear way, also because some of the evaluators and reviewers might not be experts in ethnobotany. Depending on the foundation, some might not even be scientists. Also, the collaboration of experts in different disciplines in ethnobotanical projects may improve the quality of the proposal and the relevance of the methodological approaches.

Explaining scientific theories/results is different than explaining how you will demonstrate/obtain them. The goal of writing a project proposal is to convince funders that your project is worthy of being funded. A good trick would be to make the application easy to navigate and understand. Formatting is also important: the correct, and consistent, use of fonts, headings and spacing could improve the readability and appearance of a proposal. General tips on this topic may be found in a variety of books and papers available on the web.

Ideas. Find a good idea. It is a jungle out there and a researcher has to survive by creating his/her own niche. The idea, on which the project is developed, has to be original. If your idea is new or takes a novel approach, it is important to support its potential and to detail the research background that could confirm its originality. The proposal must explain and support the idea in detail in order to convince the proposals' evaluators, and should explain why it is a good idea. Ethnobotany has many possible and dif- 
ferent applications; it has connections with multiple topics and disciplines. There are still many unexplored or understudied areas, and a variety of methodologies that can be used to conduct ethnobotanical research on cultures that are moving, changing and quickly disappearing.

Background information. Get ready! The following step after defining the idea of the project is to start gathering background information and documentation. A good knowledge of the background information is always helpful in making the proposal writing easier. A good strategy for starting the drafting of the proposal is to create an outline of the required sections and to start writing down ideas, sentences and citations that might be used in the different points of the proposal and to define the structure of the argumentation. After finishing the initial draft, the proposal itself has to be developed. In ethnobotanical studies, background information generally includes data on cultural aspects of the target group, on the environment, habitats and flora of the research area, possible methodologies, legal restrictions and permissions required, etc. (see also other sections).

Network. Find the right collaborators. A network may be constituted of two different kinds of collaborators: people who can revise the project (making suggestions and critiques) before submitting the proposal and people who will effectively be collaborators during the project. The first group of people would be useful both during the writing process and at the end for a critical revision of the work. The second group of people is necessary for many reasons: collaboration is always fruitful and ethnobotanical studies are often carried out pretty far from the researcher's institution. In projects with such large dimensions a network of collaborators is necessary, and if the project is abroad, local collaborators to include in the project may be essential. One way to expand this network is to prepare many copies of the project fiche or summary (see below) and attend a congress/conference, where it is likely to find good research partners and is possible to distribute the copies attaching a contact card.

\section{Section Framework}

The Title. It is important to find a title or acronym that briefly, honestly, and succinctly explains the main idea of the project. Using an effective, clear but short title works much better than a long and complicated one. Moreover, the granting agencies would desire to disseminate news and continued results of your research using the title of the project (Bordage \& Dawson 2003), thus the title may stick to the research for a long time. Finally, a good title, and proper keywords (as for example, medicinal plants, ethnobotany, traditional knowledge), may help the funders to identify the best reviewers for the project.

The Abstract, The project fiche or Summary. This is effectively the summary of the project and it should be pre- sented in a brief and simple way. The abstract has to also be understood by people who are not ethnobotanists, and possibly non-scientists. It could influence the way reviewers would approach, and thus judge, the project. A good abstract is made of one or two sentences from each part of the project proposal: it should explain the idea and the objectives, describe the methodologies and activities to be carried out by the group of collaborators and introduce the importance of the expected outputs. This represents the chance to grab the evaluator's attention.

The project fiche or summary is a short description of the project and it could be substituted by an abstract, but it is usually more schematic and briefly describes requests and plans. The parts are usually listed in a logical sequence that follows the organization of the entire project. This may be a key section since it would be the first part reviewers will read and could convince the evaluators to go through the rest of the document. It should include: the title, the location (where the research will be carried out), the objectives of the project (what is the focus of the project), the target group (who the participants are going to work with), the expected results (and expected outputs), the main activities (a short description of the project), strengths of the project (network resources/skills/facilities), who the participants are [the Principle Investigator $(\mathrm{PI})$ and the Co-PIs, the other collaborators that are listed within the project], duration of the project and costs (the total amount requested). A suggestion may be to add a sentence on what would be plans for financing the execution of the project in the future or if there will be other funding to support extra activities related to the project. Special emphasis should be given to the benefits for the target group and if there would be any educational activities connected to the research.

Objectives. The objectives of the project are very important and should be clearly stated. They can be structured in two parts: a short conceptual narrative which is then followed by the specific aims, which are better to be organized as bullet points. The methods, the outcomes and the organization of the project should be clearly related to the objectives. A good way to relate the objectives with the other parts of the project is to formulate them as questions, and then to find methods to answer these questions and the possible related outcomes.

This is a good place to introduce the project hypothesis, which should be also supported by literature (state of the art) or preliminary data. Many ethnobotanical projects are focused on the exploration of under-explored areas, but these kinds of projects have a small element of novelty. It is important to highlight possible applications of the ethnobotanical data, new methodologies, new theories, new models coming from a model implementation, or the possibility to use the knowledge obtained from the research, to create opportunities or generate resources for local people. Whatever the choice, it should be well mo- 
tivated and demonstrate the participants' skills in critical thinking. Finally, the objectives need to be reasonable: it is important to be sure to have the necessary resources to obtain the expected results and that they are achievable within the specified time period.

State of the Art. In this section, the knowledge gap that the project may fill is reported, and the uniqueness of the proposed approach should be demonstrated. This part should introduce the background of the research, and should help the evaluator to understand the reason for selecting the specific topic. In writing a paper we are used to stating something and citing references, reducing the explanations, and addressing the reader to find the cited paper for more information. In a project proposal this style should be avoided, since the evaluators usually have to deal with many applications and they need to quickly be made aware of the proposed issue. In this section the grant writer has to demonstrate a broad knowledge of the topic and to make evident that a thorough review of the appropriate literature has been carried out. This review will also prevent wasting time by repeating or duplicating research that has already been accomplished. Also, it will help bring a better focus to the research idea. A good strategy might be to use a logical sequence of sentences: starting from the importance of ethnobotany in the chosen context, list all the previous studies for the proposed research area while defining the gap that the study will fill, define the background of the chosen approach/analysis and specify why it would be useful to test it here, and define the problem to solve from a scale bigger than the case study. In case preliminary data are available, it is better to mention them here. This will serve to demonstrate the unique qualifications of the research team to conduct this research project, and show the time that the grant writer has already invested in testing the hypothesis.

Methods. This is a very important section, since here the grant writer has to demonstrate how to achieve the objectives of the project and the steps planned to do so. It might be helpful to divide this section in five parts: how, when, where, why, and the research network (discussed separately below).

How: This is the section where the actions, which are planned to collect the data that are necessary to validate/ invalidate the hypothesis or that are needed to meet the objectives, are defined. This section is also where the means and the scientific instruments/devices that will be used are described. Ethnobotanical projects often generate a lot of information through interviews. In this section it needs to be clarified which style of interviews will be used (structured, semi-structured, or unstructured). Which are the questions to be asked? Who will be the target group (ethnic group, women/men, elders, healers, etc.)? How will informants be sampled and selected? In order to document interviews video or audio recorders, GPS, and/or cameras usually are used: explain when they will be used, and how the informants' identity will be protected (considering that humans are generally involved in ethnobotanical studies it is important to state that ethical guidelines will be followed, see below). Where will the plant specimens be deposited? Will other kind of samples (e.g., soil, water) be collected? Will other analyses (such as molecular or biochemical analyses of the plant materials) be performed? The description of the analysis of data is also important: will statistical methods be used? Explain other pertinent information (use of specific software, modeling techniques, lab analyses, etc.). Describing these analyses is important, but the right balance between technical language and understandable language should be fostered. It's good to be precise, but it's best to be understood.

Where: The study will be carried out in a specific research area and in this section it should be explained why this area would be the best to explore the objectives of the project. All too often in ethnobotanical studies researchers want to study in a specific place and then find a research project that is suitable for that place. This is not advisable. The choice of field sites should be based on being the best place to answer the questions, to demonstrate/reject the hypotheses of the project or to test the specific modeling approaches. Other important factors regarding the research area include the area not having been explored before, or that the previous studies are outdated, that the area has been isolated for a long time, that there could be specific cultural features, etc. Additionally, it is important to discuss impacts and potential benefits for the local population, or that this area contains specific plants and knowledge that could be used for chemical analyses, predictive modeling, etc.

When: Research proposals need to have a specific duration and activities should be organized into a timetable. Providing a table that simply and clearly explains the time organization of the planned activities will be an asset, and will be appreciated by the grant evaluators. Timetables should specify the chronological and operational steps to be followed in order to achieve the envisaged objectives.

Why: The choice of one particular method instead of another has to be explained here and this decision has to be supported with relevant citations from recent literature, or preliminary data. As for example, sometimes it is not possible to use questionnaires because the majority of informants are not able to read, researchers will use transects in the forest because this has been demonstrated as a good method in similar contexts, etc. In case a new method will be tested, it is necessary to justify this choice: why could it work? And why the research team will be able to test this new method (required structures/facilities/ skills/collaborators)? If data from the study will be used to develop a model it is necessary to demonstrate how this could be used in other areas/contexts. 
The Research Network. This part could be included in the method section or it may stand alone, according to the grant guidelines. In this section the grant writer will list all collaborators that will be involved in the project, their qualifications, roles and how much of their time will be devoted to the project. This section could be schematic or not, according to the guidelines of the grant, in any case it is important to be sure that the personnel listed here will be included in the budget section, identifying where other funding will come from if not from the current proposal. If the research network is broad, and collaborators are from multiple institutions, it could be useful to use a schematic figure to better show and detail the research network. A broad network is usually a positive element, especially if it will not result in a dramatic increase in the budget. It is important to include all the specific expertise necessary to achieve the objectives of the project. If possible, attach a brief bio-sketch of the participants including their education background and their scientific track-record. The PI of the project is a key figure and he/she could make the difference between a funded and a rejected project. Thus, unless it is clearly stated that the grant is addressed to young researchers, it might be advisable to find a strong $\mathrm{PI}$ and list all other participants as CO-PI or collaborators. A background of funded projects as CO-PI or collaborator might greatly increase the chances of being a funded $\mathrm{PI}$ one day, much more so than a past of unsuccessful grant applications. Many ethnobotanical projects are multidisciplinary, thus it is important to find collaborators that have the right expertise for each project aim. Obviously the PI has to be an expert in the main topic of the research project and be able to coordinate all the planned activities in the different disciplines covered by the proposal.

Ethics and Plant Materials. Many scientific disciplines involve interactions with humans. This is especially true for ethnobotanical studies, where the researcher often has to deal with plants and human informants. Thus, it is important to follow some guidelines for gathering plant material and for respecting the local culture, and to be ethical in dealing with people. With regards to plants, it is important to have preliminary knowledge and be aware of the laws that govern the gathering of plants in the research areas, of rare or endangered plants, if there are some restrictions or ethical guidelines for the exporting of plant products or materials, such as the Convention on International Trade in Endangered Species of Wild Fauna and Flora (CITES). In the proposal, the grant writer should acknowledge the necessary permits and how they will be obtained. As for ethics and human subjects, it is necessary to be or become familiar with the guidelines for researchers working with people, such as the International Society for Ethnobiology, Code of Ethics (ISE 2006). Many institutions also have a Committee on Human Subjects or an Institutional Review Board, which governs the involvement of people in scientific research. Such review boards came about following the Nuremberg Trial disclosures of research and clinical trials. It is necessary to become familiar with their rules and obtain the necessary permits before applying for research funding. This will benefit the application by showing the participants' interest in being ethical researchers and adhere to methodologies that abide by these codes.

Project Description. This part might have some overlap with other parts of the proposal, but it is important to present a project with a logically flowing description. The project description may be ordered by its timetable or by descriptions of the different activities of the network, focusing on their fields of expertise. This section will include a description of the activities of the proposed research, avoiding repetition of the methodology and analyses that are planned.

Preliminary Data. It is always an advantage to have some preliminary data, but it is not usually necessary. However, if this is the case, preliminary data can show that the proposed project is realistic and that the grant writer has the required skills and determination to complete the proposed project. Moreover, publication of any preliminary data sets is a great way to demonstrate the potentiality of the research idea, and would serve as an asset to the project proposal. If there is not enough data to publish, presenting the data at a scientific congress or meeting of a scientific society may also show the potentiality of the project idea.

Outputs/Outcomes. Outcomes must be tangible and they have to be clearly detailed as well as how they will be spread out. Results should be a logical consequence considering objectives and methods of the project. It is important to be specific and clear and to be honest with consideration to the team's capabilities. A good way to define the outputs could be to identify in the project draft, what could be or not, considered a success. Preliminary data may be used to confirm/support the chosen approach/methods. Measurable outcomes could be, for example, publications, books, databases, videos, presentations, etc. Results must then be well disseminated, giving credit to the funders. The way the outcomes of the research will be spread out should be well described. Funders usually appreciate good publicity, especially if the outputs of the proposed project deal with something that could have a broad impact, for science/social issues etc. Educational outputs are generally welcome in many ethnobotanical project proposals: this could imply the local preservation of knowledge or the use of the collected information to improve/enlarge college/university programs.

The Broader Impact of your Research and the Added Val-

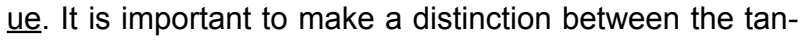
gible outputs and their possible impacts in science or in human knowledge. Ethnobotanical research often results in findings that could have great impact, e.g., for the conservation of the Intangible Cultural Heritage (UNESCO 2003). Moreover, there could be an added value, intrinsic 
to ethnobotanical research, related to cultural or environmental protection and/or awareness.

The Evaluation of Success in achieving the Aims. Granting agencies want to know how it is possible to evaluate the outputs of the project and how the success of the project will be measured. The evaluation plans should include both qualitative and quantitative data and should be considered step by step in writing the project. In ethnobotanical projects, the evaluation could be obtained through the quantification of measurable outcomes, testing of new methods that could reduce the cost of surveys, the production of concrete benefits for the local population, the development of teaching modules, etc.

The Sustainability of the Project. As ecologists or botanists we are used to seeing phrases such as "Sustainable Use of the Environment" or "Sustainable Use of Resources". However, the sustainability of a project is not related to the fact that results could be used to foster sustainable use of resources. A project is sustainable if it is successful, has the potential to attract other financial support, could contribute to the self-sufficiency of the research group (e.g., acquisition of instruments), could create positive local inputs and the community can sustain the carrying out of the project: e.g., the creation of an educational herbarium that will be maintained by local students. The sustainability of the project has to be concretely demonstrated as well as its long-term financial and social viability.

Conclusions. This section should not exceed two or three paragraphs and should briefly detail the main points of the project. It could also discuss the possible future applications of the project, the follow-up activities, the possible continuation or the potential self-sustainability of the project. It is also a good place for highlighting the importance of ethnobotany for the preservation of the local knowledge and for reducing cultural erosion, for creating resources/ opportunities for indigenous people, etc.

Citations. References are not always required in the text of a grant, however they are highly recommended, especially if the project includes cutting edge concepts or state of the art methodology. Reference literature also helps to define the background of the study. Citations can also testify to the effort used in the preparation of the project and the participants' expertise on the subject. It is important to use references properly and without overkill. Too many references can make the text less readable and unclear. It is better to cite the most relevant and current publications of the research network, in order to illustrate the team's knowledge and background in the proposed field of research.

Resources and Budget. This section defines what resources are already available for the project (research space in the involved institutions), equipment, facilities, etc. Resources should be balanced in terms of both space and finances. This section could include a brief description of the grant seeker's institution in order to define its ability to host the proposed project. A mention of some previous successful projects would aid in illustrating this point. A previous successful project carried out in similar conditions/areas or on related topics would be an asset.

Budgets are often very schematic although sometimes they are more complex than others. However, the guidelines for grant submissions from the funding source will usually have a template or a format to follow. Check carefully which costs are eligible, and if there is a co-funding requirement. If so, ask what kind of costs can be shared, these often include facilities, research space, laboratories, equipment (e.g., a detailed inventory of the equipment currently owned by the supporting institution and its cost) and personal costs (if some participants are already paid by an institution, their time dedicated to the project may be considered as shared cost). The budget includes all the costs related to the planned activities, such as, personnel, travel costs, equipment, supplies, interpreters or guides, publication costs, mail costs, etc. Grant applications often have a budget justification section. However, if this section is not required, it can still be helpful to add a short explanation for each item. Be specific about planned expenses, an amount too rounded off could sound approximated. Considering ethnobotanical projects, staff is one of the main costs in a budget. This includes consultants, interpreters, translators, local guides, and research and collection assistants (some of these figures may be listed in Services Costs). If the budget is too high in comparison with the outcomes, looking for volunteer personnel is a good way to offset the budget. Writing subsequent parallel grants is another way to allow for excesses in budget. There needs to be a balance between budget and planned activities. If the budget is unrealistically low in relation to the number of planned activities the proposal could be rejected for this as well.

(Optional) Cover Letter. The cover letter is an optional element of the grant package: it is sometimes requested by foundations or corporations. Although it should introduce the project, it is better to write the cover letter when the preparation of the project proposal is finalized. Do not enclose a cover letter if not specifically requested. The letter has to be addressed to the correct person, introduce the project and clearly specify "what you are asking for, how much and for what" (Carlson \& O'Neal-McElrath 2008). The cover letter should be brief, effective, clear, informative of the project, and should explain how this project fulfils the aims of the foundation or funding source. It could be useful to highlight any support that the community of target group has shown to the grant seeker in this letter.

\section{Following actions}

Grant review procedures vary widely and a long time may pass before getting a response. When responding to re- 
views, always be kind and formal. Even if the project has not been granted, it is possible the next one would be, so cultivate contacts. Previous knowledge is always an advantage and can increase the chances of a funded project in the next call of the same granting agency.

If the project has been funded, be professional and take this opportunity to implement a high quality research project and manage any issue in a long term perspective (i.e., renewal of contracts, future collaborations, etc.) and build a profitable relationship with the funders. For example, it would be nice to send a letter of acknowledgement. It is important to meet all reporting deadlines. These vary widely, from one page letters briefly detailing the progress of the project to multiple sectioned full reports detailing all aspects of progresses to date. This could help in keeping them interested in the specific research and in financing related projects. Foundations have been known to fund multiple stages of projects that meet their organization's aim and that they find to be worthwhile.

\section{Part 2}

In this second part the "tips and tricks" of ethnobotanists with experience in grant writing are reported. Comments and suggestions were obtained through semi-structured interviews between May and July 2011. A total number of nine Interviews were carried out by the first author during the Society of Ethnobiology Meeting (SoE) (Columbus, $\mathrm{OH}, \mathrm{USA}$ ), the Ethnobotany meeting of the Italian Botanical Society (SBI) (Rome, Italy), and the Society for Economic Botany Meeting (SEB) (St. Louis, MO, USA). Informants were made aware of the scope of the interviews and Prior Informed Consent was always requested and obtained. Comments and suggestions are summarized in Table 1 and they are organized in sets of main concepts.

Table 1. Comments and suggestions obtained through semi-structured interviews in 2011 with Grant seekers (GS) and Grant Makers (GM) at the Society of Ethnobiology Meeting (SoE) (Columbus, OH, U.S.A.), the Ethnobotany meeting of the Italian Botanical Society (SBI) (Rome, Italy), and the Society for Economic Botany Meeting (SEB) (St. Louis, MO, U.S.A.).

\begin{tabular}{|c|c|c|}
\hline General Concept & Informant's Suggestion & Informants \\
\hline $\begin{array}{l}\text { Preliminary } \\
\text { actions }\end{array}$ & $\begin{array}{l}\text { The first thing I do when I have to prepare a grant proposal is to sum up all my } \\
\text { ideas in a big picture and from it I start to create flow charts. }\end{array}$ & GS at SoE \\
\hline $\begin{array}{l}\text { Preliminary } \\
\text { actions }\end{array}$ & $\begin{array}{l}\text { The first thing I do before starting a proposal is to look for friends. I like to } \\
\text { collaborate with people who are friends, people I like (not necessarily in my same } \\
\text { dept.) because it is the only way to really put energy in what you are doing. If my } \\
\text { collaborators are friends I am more than happy to share my success with them. "I } \\
\text { want people I like to have success". "Ideas/credits - if you are selfish it does not } \\
\text { work". }\end{array}$ & GS at SoE \\
\hline $\begin{array}{l}\text { Preliminary } \\
\text { actions }\end{array}$ & $\begin{array}{l}\text { The first thing before starting to write a grant is to find a good idea. It has to be } \\
\text { original or improve other studies filling any eventual gap, prosecute their research } \\
\text { or define how you would be successful in case they failed. }\end{array}$ & GS at SEB \\
\hline $\begin{array}{l}\text { Preliminary } \\
\text { actions }\end{array}$ & $\begin{array}{l}\text { The first step is to collect information from literature and then analyze data. What } \\
\text { are these data telling me? Also, in some papers possible development of the } \\
\text { research may be written and other hypotheses to be tested are suggested. }\end{array}$ & GS at SEB \\
\hline $\begin{array}{l}\text { Preliminary } \\
\text { actions }\end{array}$ & $\begin{array}{l}\text { I usually look for a grant call and then I organize a brainstorm with my colleagues } \\
\text { to find a good and appealing idea that can fit into the scope of the call. You have } \\
\text { to read the guidelines carefully: you might be excited by your great idea but } \\
\text { sometimes this could make you blind in respect of the aims/mission of the grant. }\end{array}$ & GS at SBI \\
\hline $\begin{array}{l}\text { Preliminary } \\
\text { actions }\end{array}$ & $\begin{array}{l}\text { The first thing I do is to carefully read the guidelines, make a list of required } \\
\text { documents and create a bullet point list of things to do. }\end{array}$ & GS at SEB \\
\hline $\begin{array}{l}\text { Preliminary } \\
\text { actions }\end{array}$ & Select the proper agency for funding your project, not the inverse. & GS at SEB \\
\hline $\begin{array}{l}\text { Preliminary } \\
\text { actions }\end{array}$ & I seek for coherence between the project and the aims of the Grant maker. & GS at SBI \\
\hline $\begin{array}{l}\text { Preliminary } \\
\text { actions }\end{array}$ & $\begin{array}{l}\text { I try to fit my skill and competence into the focus/scope of the grant. In case } \\
\text { there are no restrictions as regards to the focus of the grant (wide panorama of } \\
\text { disciplines, like national granting schemes) I try to develop a project that best } \\
\text { meets my scientific profile (according to what colleagues/scholars/scientists } \\
\text { expect from me). }\end{array}$ & GS at $\mathrm{SBI}$ \\
\hline $\begin{array}{l}\text { Preliminary } \\
\text { actions }\end{array}$ & I usually write in a very schematic way, not wordy, clear, using bullet points often. & GS at SBI \\
\hline
\end{tabular}




\begin{tabular}{|c|c|c|}
\hline General Concept & Informant's Suggestion & Informants \\
\hline $\begin{array}{l}\text { Preliminary } \\
\text { actions }\end{array}$ & $\begin{array}{l}\text { There should be a good idea, but it is not a critical point since, dealing with } \\
\text { academic people, it is pretty common that there will be many good ideas. A good } \\
\text { idea is a minimum requirement. }\end{array}$ & GS at SoE \\
\hline $\begin{array}{l}\text { Preliminary } \\
\text { actions }\end{array}$ & $\begin{array}{l}\text { Sometimes during brainstorms, people come out with good ideas that are not } \\
\text { good for the considered call, but these ideas are kept apart and then used later } \\
\text { with the right grant call. }\end{array}$ & GS at $\mathrm{SBI}$ \\
\hline $\begin{array}{l}\text { Preliminary } \\
\text { actions/outcomes } \\
\text { and outputs }\end{array}$ & $\begin{array}{l}\text { Make sure that there is a need for your idea. A well structured proposal, with a } \\
\text { good idea, could be rejected if there is no effective need for the expected outputs, } \\
\text { it has no benefits for the community, it has only speculative research outputs. }\end{array}$ & GM at SoE \\
\hline $\begin{array}{l}\text { Preliminary } \\
\text { actions/resources } \\
\text { and budget/ } \\
\text { outcomes } \\
\text { and outputs }\end{array}$ & $\begin{array}{l}\text { Sometimes, even if your project is pretty good, it may not be granted since there } \\
\text { are calls that are very busy so only very highly qualified groups are granted. In } \\
\text { other occasions, your project is rejected because you try to stretch your ideas } \\
\text { in a wrong context/call (like the relevance of your project does not fit well in the } \\
\text { mission of the grant maker). Other times there are few errors that might cost you } \\
\text { the rejection: as for example, an unbalanced ratio between costs and benefits, or } \\
\text { the fact that the outputs and their dissemination are not adequate. }\end{array}$ & GS at SBI \\
\hline Abstract & $\begin{array}{l}\text { Select the proper keywords: they are used to select evaluators. If they do not } \\
\text { match with your research you may be rejected since your proposal may be judged } \\
\text { by an evaluator who deals with other disciplines. }\end{array}$ & GS at SEB \\
\hline $\begin{array}{l}\text { Project } \\
\text { description }\end{array}$ & $\begin{array}{l}\text { I usually try to be clear in describing the project, using figures to illustrate the } \\
\text { network, the connections within the group and the planned activities. }\end{array}$ & GS at SEB \\
\hline Objectives & $\begin{array}{l}\text { Specific aims should not be more than three or four and it would be better if they } \\
\text { are somehow correlated/connected. }\end{array}$ & GS at SoE \\
\hline Objectives & $\begin{array}{l}\text { A first reason for rejection is that objectives are not clear, or are not related to the } \\
\text { focus of my agency. However, sometimes I accept proposals even if they are not } \\
\text { so well written, or objectives are not clear, in case these proposals come from the } \\
\text { community. }\end{array}$ & GM at SoE \\
\hline Objectives & $\begin{array}{l}\text { Projects are rejected when objectives are not clear, or they might be clear but do } \\
\text { not have appeal. }\end{array}$ & GS at SBI \\
\hline Objectives & $\begin{array}{l}\text { Grants are rejected because they are descriptive. They have to be hypothesis- } \\
\text { driven and they need sound methodology. }\end{array}$ & GS at SEB \\
\hline $\begin{array}{l}\text { The state } \\
\text { of the art }\end{array}$ & $\begin{array}{l}\text { A general problem is that people are not well aware of the state of the art of } \\
\text { their research (so they do not have a deep knowledge of the background and do } \\
\text { not know that their ideas may be out of date). Thus, it is very important to detail } \\
\text { the state of the art of your research proposal. Sometimes, since ethnobotany } \\
\text { is interdisciplinary, background studies may be listed/incorporated in other } \\
\text { disciplines. }\end{array}$ & GS at SEB \\
\hline $\begin{array}{l}\text { Methods/ } \\
\text { timetable }\end{array}$ & Methods have to be clear and the timetable needs to be realistic. & GS at SBI \\
\hline Network & $\begin{array}{l}\text { Once I have found a grant and a good idea, I start to look for the proper network. } \\
\text { Network is an important part of preparing a project: it has to be efficient. }\end{array}$ & GS at SBI \\
\hline Network & $\begin{array}{l}\text { Network is important. In multidisciplinary projects it could be useful to create few } \\
\text { sub-teams working on different aspects of the project. }\end{array}$ & GS at SEB \\
\hline Network & $\begin{array}{l}\text { Having a good network is very important. I would prefer to work with people coming } \\
\text { from developing countries and with people working in different fields/disciplines. }\end{array}$ & GS at SEB \\
\hline Ethics & $\begin{array}{l}\text { Research, in order to be considered good, should come from the community or } \\
\text { at least have the support of the community (letter of support from members of the } \\
\text { community). }\end{array}$ & GM at SoE \\
\hline Ethics & $\begin{array}{l}\text { Ethics are a key issue, but if the researchers come from the same country where } \\
\text { the research will be carried out, this factor is less problematic. Also it is very unlikely } \\
\text { to obtain a new drug from information gathered through ethnobotanical interviews. }\end{array}$ & GS at SEB \\
\hline
\end{tabular}




\begin{tabular}{|c|c|c|}
\hline General Concept & Informant's Suggestion & Informants \\
\hline $\begin{array}{l}\text { Outcomes/ } \\
\text { Outputs }\end{array}$ & Usually are books and articles. & GS at SoE \\
\hline $\begin{array}{l}\text { Outcomes/ } \\
\text { Outputs }\end{array}$ & Results must always have long term effects. & GS at SBI \\
\hline $\begin{array}{l}\text { Outcomes/ } \\
\text { Outputs }\end{array}$ & $\begin{array}{l}\text { A key point is that you have to be sure that you will be able to obtain your expected } \\
\text { results. It is not important if they are positive results, they might also be negative, } \\
\text { but they have to be meaningful for the advancement of science/knowledge. }\end{array}$ & GS at SoE \\
\hline $\begin{array}{l}\text { Outcomes/ } \\
\text { Outputs }\end{array}$ & $\begin{array}{l}\text { I always try to achieve results that may have some benefits for the local community } \\
\text { (especially addressing the local conservation of knowledge). }\end{array}$ & GS at SEB \\
\hline $\begin{array}{l}\text { Outcomes/ } \\
\text { Outputs }\end{array}$ & $\begin{array}{l}\text { I try to develop a project that can bring something useful and concrete for the } \\
\text { community. I do not like to be rejected because my project does not bring anything } \\
\text { to people. I always add to projects actions that can really produce something } \\
\text { for the community. Concerning this point, I usually try to highlight the potential } \\
\text { outcomes, concrete objectives and potential long term outputs. }\end{array}$ & GS at SBI \\
\hline Broader impact & $\begin{array}{l}\text { Sacred areas, cultural key stone species may also be important for environmental } \\
\text { protection. }\end{array}$ & GS at SEB \\
\hline $\begin{array}{l}\text { Resources } \\
\text { and Budget }\end{array}$ & $\begin{array}{l}\text { I prefer not to have constrains as regards to budget. The provisional budget needs } \\
\text { to cover all the required actions of the project. It is more important to pursue the } \\
\text { aim of the project and collect all the necessary data than to limit expenses and } \\
\text { have poor data. }\end{array}$ & GS at SBI \\
\hline Cover letter & $\begin{array}{l}\text { A common problem is that I have no idea who the grant seekers are. In these } \\
\text { cases it could be important to have preliminary contacts with me (the grant maker). } \\
\text { I would appreciate a letter of introduction from the grant seekers BEFORE they } \\
\text { apply for the grant. }\end{array}$ & GM at SoE \\
\hline Following actions & $\begin{array}{l}\text { Do expect to be rejected, it is part of the process, do not take it personally "no } \\
\text { problem, move on and try again". "You win when you lose some". Finally, if you } \\
\text { have been rejected once, and you want to apply again for the same grant in the } \\
\text { future, start your new proposal saying that you have been rejected the last time } \\
\text { and that you did all the required changes (that were suggested). Make clear what } \\
\text { you have changed from the last proposal. }\end{array}$ & GS at SoE \\
\hline Following actions & $\begin{array}{l}\text { Learn from your mistakes, be humble and accept comments. When the list of } \\
\text { granted projects is published, study the ideas, projects, research groups that have } \\
\text { been awarded and try to understand the main reason for their having been granted } \\
\text { and your having been rejected. }\end{array}$ & GS at SBI \\
\hline $\begin{array}{l}\text { Various } \\
\text { comments }\end{array}$ & $\begin{array}{l}\text { Sometimes it is clear that the grant seekers just look for money. "If you just want } \\
\text { to get money, it is not going to work". }\end{array}$ & GM at SoE \\
\hline $\begin{array}{l}\text { Various } \\
\text { comments }\end{array}$ & $\begin{array}{l}\text { It should be clear that the grant seekers have passion for the topic and if so, it } \\
\text { is pretty easy to understand it when you are evaluating a proposal. Thus, if your } \\
\text { intention is to making something concrete, positive for the community and that you } \\
\text { are doing that because you LIKE and WANT to do that, it would result crystal clear } \\
\text { from the proposal. }\end{array}$ & GM at SoE \\
\hline $\begin{array}{l}\text { Various } \\
\text { comments }\end{array}$ & $\begin{array}{l}\text { I usually try to find what could be the critical points for the evaluation, which can } \\
\text { be the points that could make a difference between a granted and an unfunded } \\
\text { project and I try to find out what might be the review processes. }\end{array}$ & GS at SoE \\
\hline $\begin{array}{l}\text { Various } \\
\text { comments }\end{array}$ & $\begin{array}{l}\text { I have a wide experience on projects granted by the EU commission. I know the } \\
\text { projects that have been granted and thus I can usually see which project could be } \\
\text { granted in relation to the mission of the EU Commission. You have to be always } \\
\text { updated, take part to meetings and conferences, exchange ideas, reasoning in } \\
\text { a strategic way, connecting/relating things that apparently have no relation, look } \\
\text { outside the schemes, forecasting future trends. }\end{array}$ & GS at SBI \\
\hline
\end{tabular}




\section{Conclusions}

The authors hope that this paper will help readers in writing better ethnobotanical grant proposals. However, since writing a proposal is usually complicated and there could be a lot of different formats and guidelines it may be helpful to look for alternative and complementary sources for grant writing and funding information, including advice from past awardees from the particular granting agency. Publically funded institutions or foundations generally provide lists of past awardees, including their home institutions and contact information. Finally, the authors hope that this paper will help young researchers to improve the quality of their grant writing in order to have more funding in the field of ethnobotany and thus help the advance of this discipline.

\section{Acknowledgements}

Many thanks are due to all the informants who shared with us their experience and knowledge in writing ethnobotanical research projects.

\section{Literature Cited}

Bordage, G. \& B. Dawson. 2003. Experimental study design and grant writing in eight steps and 28 questions. Medical Education 37:376-385.
Browning, B.A. 2008. Grant Writing for Dummies. Third Edition, Wiley Publishing Inc., Hoboken, New Jersey, U.S.A.

Carlson, M. \& T. O'Neal-McElrath. 2008. Winning Grants, Step by Step. Third edition, Jossey-Bass, San Francisco, California, U.S.A.

Karsh E. \& A.S. Fox. 2009. The Only Grant-Writing Book You'll Ever Need: Top grant writers and grant givers share their secrets. Third Edition. Basic Books, New York, New York, U.S.A.

ISE. 2006. International Society of Ethnobiology Code of Ethics (with 2008 additions). www.ethnobiology.net/ethics.php

Nebiu, B. 2002. Developing Skills of NGOS. Project Proposal Writing. Edited by I. Simon \& C. Stancu. The Regional Environmental Center for Central and Eastern Europe, Szentendre, Hungary.

UNESCO. 2003. Convention for the Safeguarding of the Intangible Cultural Heritage. United Nations Educational, Scientific and Cultural Organization, 32nd General Conference, Paris, 17 October 2003. 